\title{
The role of the land use, land use change and forestry sector in achieving Annex I reduction pledges
}

\author{
Giacomo Grassi • Michel G. J. den Elzen • \\ Andries F. Hof • Roberto Pilli • Sandro Federici
}

Received: 13 April 2012 / Accepted: 28 August 2012 / Published online: 2 October 2012

(C) The Author(s) 2012

\begin{abstract}
Annex I Parties may receive credits or debits from Land Use, Land Use Change and Forestry (LULUCF) activities, contributing to achieving individual emission reduction targets. In the Durban climate negotiations, Parties agreed new LULUCF accounting rules for the second commitment period of the Kyoto Protocol (CP2). By using these new rules, this paper presents key differences among Parties at the minimum (assuming no additional action) and potential (assuming additional actions) contribution of the forest-related LULUCF activities in achieving the pledges for 2020. Overall, the potential contribution of LULUCF is relatively modest (up to about $2 \%$ of 1990 emissions) for the EU, the Annex I Parties likely joining the CP2, and for the Annex I Parties that joined the CP1 as a whole. However, for specific Parties, LULUCF can make a substantial contribution to achieving the pledges. For New Zealand, for instance, the potential contribution of future LULUCF credits may equal $33 \%$ of its 1990 emission level. For Australia, the pledges are expressed relative to 2000 emission levels including LULUCF emissions. Given that LULUCF emissions have strongly declined between 1990 and 2000, and a further decline in foreseen by 2020 (based on Australia's projections), the minimum contribution of LULUCF to meet the Australian pledges appears to be about $19 \%$ and $7 \%$ relative to its 1990 and 2000 emission level, respectively. A further $3 \%$ potential contribution is estimated from additional actions.
\end{abstract}

Electronic supplementary material The online version of this article (doi:10.1007/s10584-012-0584-4) contains supplementary material, which is available to authorized users.

G. Grassi $(\bowtie) \cdot$ R. Pilli $\cdot$ S. Federici

European Commission, Joint Research Centre, Institute for Environment and Sustainability,

Via E. Fermi 2749, I-21027 Ispra (VA), Italy

e-mail: giacomo.grassi@jrc.ec.europa.eu

M. G. J. den Elzen • A. F. Hof

Department of Climate, Air and Energy, Netherlands Environmental Assessment Agency (PBL), P.O. Box 303, 3720 AH Bilthoven, The Netherlands 


\section{Introduction: new LULUCF rules agreed in Durban}

In the United Nations climate negotiations urgent action was called for to limit global warming below $2{ }^{\circ} \mathrm{C}$ above pre-industrial levels. 42 Annex I Parties (developed countries) have submitted quantified economy-wide emission targets for the year 2020. ${ }^{1}$ These pledges have subsequently been included in the 2010 Cancún Agreements (UNFCCC 2010). While most Parties acknowledged that the Land Use, Land Use Change and Forestry (LULUCF) sector may have significant implications for the ambition level of their target, a consistent set of estimates on the possible contribution of LULUCF to achieving the pledges is still lacking (UNFCCC 2012b). This paper focuses on the role of the LULUCF sector in achieving the pledges made the Annex I Parties likely joining the second commitment period of the Kyoto Protocol (CP2), and CP1 Parties. ${ }^{2}$

The LULUCF sector comprises different activities which may remove or add greenhouse gas (GHG) from/to the atmosphere. During the first commitment period of the Kyoto Protocol (CP1), a series of complex accounting rules determine the amount of credits or debits from LULUCF activities. Credits contribute to achieving individual reduction targets, while debits increase the reduction required outside the LULUCF sector in order to meet commitments. Under these rules, the accounting is mandatory for afforestation/reforestation (AR) and deforestation (D) since 1990 and is voluntary (though mandatory if elected) for forest management (FM), cropland and grazing land management, and revegetation. Given the consensus on the need to improve the current rules, new LULUCF accounting rules for Annex I Parties in the second commitment period (CP2) were finally agreed on December 2011, at $\mathrm{CMP}^{3}$ in Durban (UNFCCC 2012a). The main features of the new LULUCF rules include:

- Accounting of FM becomes mandatory. Credits and debits during the CP2 will be calculated by subtracting a 'reference level' (FM-RL) from the reported, actual emissions or removals. There is a cap on credits equal to $3.5 \%$ of base year emissions ${ }^{4}$ excluding LULUCF;

- New rules for harvested wood products and natural disturbances;

- Fluxes from wetland drainage and rewetting may be accounted if elected;

- Accounting of AR, D and the other activities remains essentially the same.

An analysis of the new LULUCF rules may be found elsewhere (e.g. Macintosh 2011; Grassi 2012a). In this paper, we briefly explore the possible quantitative contribution of the forest-related LULUCF activities (AR, D and FM) to achieving reduction pledges by Annex I Parties during the CP2 (assumed 2013-2020). In order to explore a wide range of potential contribution, two scenarios are analysed: a minimum level, assuming no additional LULUCF mitigation actions beyond business-as-usual (BAU), and a potential level, estimated through expert-based assumptions on the impact of feasible additional actions. The estimates in this paper represent a refinement, and update with the new LULUCF rules, of the estimates included

\footnotetext{
${ }^{1}$ For an overview of the assumptions and conditions of the reduction pledges of Annex I Parties, see UNFCCC (2012b).

${ }^{2}$ The analysis presented here considers all Annex I Parties excluding USA, Turkey, Kazakhstan, Liechtenstein and Monaco (i.e., the CP1 Parties). Throughout the paper, the "likely CP2 Parties" indicate the CP1 Parties, excluding Canada, Japan and Russia.

$37^{\text {th }}$ Conference of the Parties serving as the Meeting of the Parties to the Kyoto Protocol (CMP7)

${ }^{4}$ In this study, with base year emissions we refer to the aggregate anthropogenic carbon dioxide equivalent emissions of the GHGs listed in Annex A sources, taken from 2012 GHG inventories, and we further considered the provisions of Art. 3.7 of the Kyoto Protocol where relevant.
} 
in den Elzen et al. (2011). Given the complexity and the uncertainty of the LULUCF sector, the aim of the paper is not to estimate accurately the expected credits for each Party, but rather to highlight the likely major differences in the contribution of LULUCF to achieving reduction pledges among Annex I Parties.

\section{Methodology: calculating LULUCF credits}

The calculations of the LULUCF credits for Annex I Parties during the CP2 are based on the JRC LULUCF tool (Grassi 2012b). The tool contains: 1) historical data from GHG inventories (1990-2010), updated to data available as of May 2012;2) additional GHG data submitted by Parties during the UNFCCC negotiations, up to December 2011;3) elaboration of country data using transparent assumptions (e.g., extrapolation). In this paper we present estimates for the minimum (without additional actions) and the potential (with additional actions) level of credits/debits for AR, D and FM. Other LULUCF activities are not assessed, due to lack of reliable data. However, it is likely that their overall contribution will be smaller than that of AR, D and FM. ${ }^{5}$

Credits for afforestation/reforestation (AR) and deforestation (D) The minimum estimates for AR and D are based on Parties' projections, when available, or alternatively on the average of 2008-2010 data under the Kyoto Protocol. The potential estimates are based on: (i) Parties' projections, when available, ${ }^{6}$ multiplied by a correcting factor (1.1 for $\mathrm{AR}$ and 0.8 for $\mathrm{D}$ ) to estimate the additional mitigation potential, or alternatively on (ii) elaborations of historical data from the GHG inventories. In the latter approach, a linear extrapolation of the 1990-2010 data is used for AR (assuming this approach already incorporates additional mitigation activities) and the average of 2008-2010 data, multiplied by 0.8 , is used for D. The assumptions made for AR are based on the analysis of trends from GHG inventories in relation to the range of harvesting ages in most Annex I countries. ${ }^{7}$ The choice of different correcting factors for AR and D is based on the empirical evidence that additional AR actions (e.g. higher planting rate, longer rotations) have a modest impact on the short-term sink (i.e. up to 2020), while a relatively higher short-term impact may be assumed for additional policies aimed at reducing emissions from $\mathrm{D}$. The above assumptions on feasible additional actions appear consistent with the information available from the countries and with the scenarios explored in the existing literature. $^{8}$

Credits or debits from forest management (FM) The JRC LULUCF tool calculates the minimum FM credits using Parties' projections and the forest management reference levels

\footnotetext{
${ }^{5}$ E.g., based on the available information, the order of magnitude of the expected credits from cropland management will likely be less than $15-20 \mathrm{Mt} \mathrm{CO}_{2}$ in both Canada and the EU.

${ }^{6}$ Parties' projections were in general available where credits or debits are expected to be relevant (e.g. emission projections of D for Australia and Canada, and AR for New Zealand and Australia).

${ }^{7}$ E.g. with the conditions typical of many Annex I countries (e.g. harvesting age at 20-40 years and a stable or decreasing planting rate), under a business as usual scenario the AR sink may be expected to peak between 2010 and 2020 in most conditions.

${ }^{8}$ E.g.: - A submission of New Zealand to UNFCCC suggests that the impact of different assumptions on planting rates and harvesting ages on the AR sink may be significant in the long-term, but is about $\pm 10 \%$ for 2013-2020 (http://unfccc.int/files/kyoto protocol/application/pdf/newzealandlulucf150909.pdf).

- Macintosh (2011) used a scenario of reduction of emissions from D in Australia ranging from 0 to about - $30 \%$ compared to current levels.
} 
(FM-RLs) submitted by Parties in 2011 and agreed in Durban (UNFCCC 2012a). For Norway, Russia and Belarus, the FM-RL is based on 1990 FM sink. For Japan, FM-RL is set to zero. For the majority of Annex I Parties (i.e. Australia, Canada, Croatia, EU, New Zealand, Switzerland and Ukraine), the FM-RL is based on BAU projected emissions and removals for the period 2013-2020: therefore, in theory, there will be no FM credits for these Parties without changing current FM practices. However, due its relative cost-effectiveness, it seems likely that countries will undertake additional FM mitigation practices. Estimating the full FM mitigation potential in these cases would be a complex and uncertain exercise, because this depends on both (a) the enhancement of carbon sink within the forest and in harvested wood products, and (b) the carbon substitution of energy and of other materials. In this paper, we provide estimates on the potential FM credits linked to a feasible enhancement of carbon sink within the forest (as compared to the FM-RLs), without considering trade-offs between the various options (e.g. Böttcher et al. 2012). To this aim, we estimated the possible impact of a $10 \%$ reduction of harvest as compared to the level indicated in Parties' projections. This approach builds on a number of key assumptions: (i) in the short term, the harvest level is the main driver of the net forest $\operatorname{sink}^{9}$; (ii) while significant fluctuations in harvest may occur for several reasons, we believe than a $10 \%$ reduction of harvest over 8 years (e.g. implemented by longer rotation lengths) may realistically simulate for most countries policies to promote short-term carbon stock increases in forests ${ }^{10}$; (iii) the reduction of harvest does not affect the harvested wood products (i.e. it occurs at the expense of bioenergy); (iv) the harvest included in the FM-RLs agreed in Durban in general represents a BAU scenario ${ }^{11}$; and (v) the FM reporting during the CP2 will be methodologically consistent with the FM-RL. ${ }^{12}$

The impact of a $10 \%$ reduction of harvest on forest sink was derived using two approaches:

(a) Existing studies: for the EU, Böttcher et al. (2012) provided model estimates of the FM sink up to 2020 , showing that a $10 \%$ reduction of harvest would increase the sink by approximately $20 \%$ (average of two models). For Australia, Macintosh (2011) provided estimates on the potential FM credits from native forests under various assumptions of future harvest rates; in this case, we scaled the results to a reduction of $10 \%$ harvest.

(b) Empirical and crude estimation of the expected credits as a result of a $10 \%$ reduction of future harvest: in this case, we estimated the impact of a $10 \%$ reduction of future harvest (as provided by the Parties in their FM-RL submissions) using the appropriate default biomass conversion and expansion factors (IPCC 2006). This approach assumes no substantial short-term impact on forest growth.

\footnotetext{
${ }^{9}$ In the short term (i.e., up to 2020), less harvest generally means lower emissions (i.e. greater net sink); however, in the medium-long term, harvest is needed to maintain a high growth rate of forests.

${ }^{10}$ The choice of the $10 \%$ is partly linked to the availability of simulations with this \% for a number of countries (Böttcher et al. 2012). For specific countries, the realistic potential of harvest reduction may be higher. Other possible practices for increasing the FM sink (e.g. thinning, changing species composition, fertilization, low-impact harvesting, improved fire/pest management, forest conservation) are not considered here because likely less important in the short-term and/or more difficult to quantify.

11 This assumption is relevant: if a country overestimated the BAU harvest in its projected FM-RL, it could get "windfall credits", i.e. credits without additional actions. The transparency of the assumptions used for FM-RLs was checked during the technical assessments carried out by UNFCCC (http://unfccc.int/bodies/awg$\mathrm{kp} /$ items/5896.php). Further assessment of these assumptions would be a difficult and controversial exercise, which goes beyond the scope of this paper.

${ }^{12}$ Here we assume that any problem on methodological consistency between FM-RLs and GHG inventories highlighted during the technical assessments carried out by UNFCCC will be addressed when accounting.
} 


\section{Results: impact of the LULUCF accounting rules}

Table 1 gives the minimum credits or debits (without additional actions) estimated for ARD and FM in the 2013-2020 period. Annex I Parties that joined the CP1 as a whole would receive credits from FM, essentially due to Russia and Japan (likely not CP2 Parties), and debits from ARD, mostly due to D emissions in Australia.

The potential amount of credits (i.e. assuming additional feasible actions) estimated for ARD and FM in the 2013-2020 period are shown in Table 2. For all CP1 Parties combined, the potential credits from AR are compensated by debits from D. However, this is not the case for individual Parties: relative to base year emissions, large AR credits are expected for New Zealand and quite substantial D debits will likely arise for Australia and Canada. With regard to FM, the following groups of Parties can be distinguished: (i) Parties which will very likely reach the FM cap equal to $3.5 \%$ of base year emissions, independently from any reduction of harvest (Russia, Norway, Japan); (ii) Parties which would reach the cap on the assumption of a $10 \%$ reduction in harvest (e.g. Canada, New Zealand); and (iii) Parties for which it is unlikely that the FM cap will be reached, unless more substantial actions are implemented (e.g. EU, Ukraine, Australia). The third group of countries have a relatively small FM sink and harvest level as compared to base year emissions. ${ }^{13}$ The potential FM credits from Parties with FM-RL either based on 1990 or set to zero (Japan), although limited by the cap, is about twice the level of Parties which use projected FM-RLs (see Table SI-1).

Overall, the contribution of LULUCF credits ranges from $1.1 \%$ to $2.1 \%$ of base year emission levels for all CP1 Parties and from $0.1 \%$ to $1.5 \%$ of base year emission levels for the likely CP2 Parties. When assessing these estimates, high uncertainties should be considered (see SI).

Table 3 presents the potential contribution of LULUCF to achieving emission targets (relative to base year emissions, excluding LULUCF unless otherwise specified) for Annex I Parties by 2020. For the EU, the LULUCF contribution may range from $0.5 \%$ to $1.8 \%$ of its base year emissions. For New Zealand, the contribution could be up to $33 \%$ of its base year emissions. For Australia the situation is complex, due to the fact that its targets $(-5 \%$ for the low pledge and $-25 \%$ for the high pledge) are relative to 2000, and include AR and D emissions (140 Mt $\mathrm{CO}_{2}$ eq in 1990, $71 \mathrm{Mt} \mathrm{CO}_{2}$ eq in 2000 and $34 \mathrm{Mt} \mathrm{CO}_{2}$ eq in $2020^{14}$ ). In Table 3, targets are expressed both relative to 1990 and 2000 emission levels; in both cases, $\mathrm{AR}$ and $\mathrm{D}$ emissions are included. Therefore, the contribution of LULUCF to the 2020 pledges can be expressed in terms of: (i) expected minimum contribution (due to the foreseen decreasing trend of net LULUCF emissions): $19.0 \%$ and $6.6 \%$ relative to 1990 and 2000, respectively; and (ii) potential additional contribution (i.e. the difference between Table 2 and Table 1): about $3 \%$ more than the minimum. ${ }^{15}$ For Canada, LULUCF may contribute up to about $1.6 \%$ of 1990 emissions. For this Party, significant

\footnotetext{
${ }^{13}$ For Australia, total forest sink is substantial compared to the emissions in the other sectors. However, the sink included in the FM-RL is small because forest area included in FM-RL is $10 \%$ of total forest area.

${ }^{14}$ For 2020 we took the average of 2013-2020 country's projections. An overview of Australia's emissions and pledges is available at: http://unfccc.int/files/bodies/awg-lca/application/pdf/20120516_aus_1520.pdf

${ }^{15}$ Estimates are as follows: (a) for the minimum: $(34-140) / 558=19.0 \%$ relative to 1990 , and $(34-71) / 565=$ $6.6 \%$ relative to 2000 ; (b) for the potential: $(17-140) / 558=22.0 \%$ relative to 1990 , and $(17-71) / 565=9.6 \%$ relative to 2000 .
} 
Table 1 Estimated minimum credits $(-)$ or debits $(+)$ from afforestation/reforestation $(A R)$, deforestation $(D)$ and forest management $(F M)$ by Annex I Parties in the period 2013-2020

${ }^{\text {a }}$ Sum of Parties above

${ }^{\mathbf{b}}$ All Parties above excluding

Canada, Japan and Russia

${ }^{\mathbf{c}}$ Without LULUCF (with the exception of Australia and

Norway). For Australia, the 1990 base year is considered, including $140 \mathrm{Mt} \mathrm{CO}_{2}$ eq emissions from $\mathrm{AR}$ and $\mathrm{D}$

\begin{tabular}{|c|c|c|c|c|c|}
\hline \multirow[t]{2}{*}{ Country } & \multirow{2}{*}{\multicolumn{2}{|c|}{$\begin{array}{l}\mathrm{AR} \mathrm{D} \\
\mathrm{Mt} \mathrm{CO}_{2}\end{array}$}} & \multirow[t]{2}{*}{ FM } & \multicolumn{2}{|l|}{ Total } \\
\hline & & & & $\mathrm{Mt} \mathrm{CO} 2$ & $\begin{array}{l}\% \text { of base year } \\
\text { emissions }\end{array}$ \\
\hline Australia & -14 & 48 & 0 & 34 & $6.1 \%$ \\
\hline Belarus & 0 & 0 & 0 & 0 & $-0.3 \%$ \\
\hline Canada & -1 & 16 & 0 & 15 & $2.5 \%$ \\
\hline Croatia & -0.1 & 0.2 & 0 & 0 & $0.3 \%$ \\
\hline EU & -54 & 29 & 0 & -26 & $-0.5 \%$ \\
\hline Iceland & 0 & 0.0 & 0 & 0 & $-4.7 \%$ \\
\hline Japan & 0 & 3.5 & -44 & -41 & $-3.3 \%$ \\
\hline New Zealand & -17 & 1.3 & 0 & -16 & $-26.6 \%$ \\
\hline Norway & -0.5 & 0.6 & -2 & -2 & $-3.2 \%$ \\
\hline Russia & -5 & 22 & -117 & -100 & $-3.0 \%$ \\
\hline Switzerland & 0 & 0.2 & 0 & 0 & $0.3 \%$ \\
\hline Ukraine & 0 & 0.1 & 0 & 0 & $0.0 \%$ \\
\hline CP1 Parties ${ }^{\mathrm{a}}$ & -93 & 120 & -164 & -136 & $-1.1 \%$ \\
\hline Likely CP2 Parties ${ }^{\mathrm{b}}$ & -86 & 79 & -2 & -10 & $-0.1 \%$ \\
\hline
\end{tabular}

Table 2 Estimated potential credits (-) and debits (+) from afforestation/reforestation $(A R)$, deforestation $(D)$ and forest management $(F M)$ by Annex I Parties in the period 2013-2020

\begin{tabular}{|c|c|c|c|c|c|c|c|c|}
\hline \multirow[t]{2}{*}{ Country } & \multicolumn{2}{|l|}{ AR } & \multicolumn{2}{|l|}{$\mathrm{D}$} & \multicolumn{2}{|l|}{ FM } & \multicolumn{2}{|l|}{ Total } \\
\hline & $\begin{array}{l}\mathrm{Mt} \\
\mathrm{CO}_{2}\end{array}$ & $\begin{array}{l}\% \text { of base year } \\
\text { emissions }\end{array}$ & $\begin{array}{l}\mathrm{Mt} \\
\mathrm{CO}_{2}\end{array}$ & $\begin{array}{l}\% \text { of base year } \\
\text { emissions }\end{array}$ & $\begin{array}{l}\mathrm{Mt} \\
\mathrm{CO}_{2}\end{array}$ & $\begin{array}{l}\% \text { of base year } \\
\text { emissions }\end{array}$ & $\begin{array}{l}\mathrm{Mt} \\
\mathrm{CO}_{2}\end{array}$ & $\begin{array}{l}\% \text { of base year } \\
\text { emissions }\end{array}$ \\
\hline Australia & -15 & $-2.7 \%$ & 38 & $6.8 \%$ & -6 & $-1.1 \%$ & 17 & $3.1 \%$ \\
\hline Belarus & 0 & $0.0 \%$ & 0 & $0.0 \%$ & -3 & $-2.2 \%$ & -3 & $-2.2 \%$ \\
\hline Canada & -2 & $-0.3 \%$ & 13 & $2.2 \%$ & -21 & $-3.5 \%$ & -9 & $-1.6 \%$ \\
\hline Croatia & -0.2 & $-0.6 \%$ & 0 & $0.6 \%$ & -1 & $-3.3 \%$ & -1 & $-3.3 \%$ \\
\hline EU & -72 & $-1.3 \%$ & 23 & $0.4 \%$ & -52 & $-0.9 \%$ & -101 & $-1.8 \%$ \\
\hline Iceland & 0 & $-6.4 \%$ & 0 & $0.0 \%$ & 0 & $0.0 \%$ & 0 & $-6.4 \%$ \\
\hline Japan & -1 & $0.0 \%$ & 3 & $0.2 \%$ & -44 & $-3.5 \%$ & -42 & $-3.3 \%$ \\
\hline New Zealand & -19 & $-31.7 \%$ & 1 & $1.8 \%$ & -2 & $-3.5 \%$ & -20 & $-33.4 \%$ \\
\hline Norway & -1 & $-1.3 \%$ & 0 & $1.2 \%$ & -1 & $-3.5 \%$ & -1 & $-3.6 \%$ \\
\hline Russia & -7 & $-0.2 \%$ & 18 & $0.5 \%$ & -117 & $-3.5 \%$ & -107 & $-3.2 \%$ \\
\hline Switzerland & 0 & $0.0 \%$ & 0 & $0.3 \%$ & -1 & $-2.0 \%$ & -1 & $-1.8 \%$ \\
\hline Ukraine & 0 & $0.0 \%$ & 0 & $0.0 \%$ & -2 & $-0.2 \%$ & -2 & $-0.2 \%$ \\
\hline CP1 Parties ${ }^{\mathrm{a}}$ & -116 & $-0.9 \%$ & 96 & $0.8 \%$ & -251 & $-2.0 \%$ & -271 & $-2.1 \%$ \\
\hline $\begin{array}{l}\text { Likely CP2 } \\
\text { Parties }^{\mathrm{b}}\end{array}$ & -107 & $-1.4 \%$ & 63 & $0.9 \%$ & -69 & $-0.9 \%$ & -113 & $-1.5 \%$ \\
\hline
\end{tabular}

a Sum of Parties above

b All Parties above excluding Canada, Japan and Russia

${ }^{\mathbf{c}}$ Without LULUCF (with the exception of Australia and Norway). For Australia, the 1990 base year is considered, including $140 \mathrm{Mt} \mathrm{CO}_{2}$ eq emissions from AR and D 
Table 3 Potential contribution of LULUCF to achieve the emission targets (based on the pledges submitted in the Cancún Agreement) for Annex I Parties in 2020

\begin{tabular}{|c|c|c|c|c|c|c|}
\hline & \multirow{3}{*}{$\begin{array}{l}2000 \\
\text { emissions, } \\
\mathrm{Mt} \mathrm{CO}_{2} \text { eq }\end{array}$} & \multirow{3}{*}{$\begin{array}{l}\text { Base year } \\
\text { emissions } \\
\mathrm{Mt} \mathrm{CO}_{2} \text { eq }\end{array}$} & \multicolumn{4}{|c|}{ Emission targets in 2020 relative to base year emissions ${ }^{\text {a }}$} \\
\hline & & & \multicolumn{2}{|l|}{ Low pledge } & \multicolumn{2}{|c|}{ High pledge } \\
\hline & & & $\begin{array}{l}\text { Excluding } \\
\text { additional } \\
\text { LULUCF } \\
\text { credits }\end{array}$ & $\begin{array}{l}\text { Including } \\
\text { additional } \\
\text { potential } \\
\text { LULUCF } \\
\text { credits }\end{array}$ & $\begin{array}{l}\text { Excluding } \\
\text { additional } \\
\text { LULUCF } \\
\text { credits }\end{array}$ & $\begin{array}{l}\text { Including additional } \\
\text { potential LULUCF } \\
\text { credits }\end{array}$ \\
\hline \multicolumn{7}{|l|}{ Australia ${ }^{\mathbf{b}}$} \\
\hline Relative to 2000 & 565 & & $-5.0 \%$ & $-2.0 \%$ & $-25.0 \%$ & $-22.0 \%$ \\
\hline Relative to 1990 & & 558 & $-3.8 \%$ & $-0.7 \%$ & $-24.0 \%$ & $-21.0 \%$ \\
\hline Belarus & & 139 & $-5.0 \%$ & $-2.8 \%$ & $-10.0 \%$ & $-7.8 \%$ \\
\hline Canada & & 592 & $2.8 \%$ & $4.4 \%$ & $2.8 \%$ & $4.4 \%$ \\
\hline Croatia & & 31 & $-5.0 \%$ & $-1.7 \%$ & $-5.0 \%$ & $-1.7 \%$ \\
\hline $\mathrm{EU}^{\mathbf{c}}$ & & 5,583 & $-20 \%$ & $-20.0 \%$ & $-30 \%$ & $-28.2 \%$ \\
\hline Iceland & & 3 & $-30 \%$ & $-23.6 \%$ & $-30 \%$ & $-23.6 \%$ \\
\hline Japan & & 1,267 & $-25 \%$ & $-21.7 \%$ & $-25 \%$ & $-21.7 \%$ \\
\hline New Zealand & & 60 & $-10 \%$ & $23.4 \%$ & $-20 \%$ & $13.4 \%$ \\
\hline Norway $^{\mathbf{d}}$ & & 41 & $-30 \%$ & $-26.4 \%$ & $-40 \%$ & $-36.4 \%$ \\
\hline Russia & & 3,349 & $-15 \%$ & $-11.8 \%$ & $-25 \%$ & $-21.8 \%$ \\
\hline Switzerland & & 53 & $-20 \%$ & $-18.2 \%$ & $-30 \%$ & $-28.2 \%$ \\
\hline Ukraine & & 930 & $-20 \%$ & $-19.8 \%$ & $-20 \%$ & $-19.8 \%$ \\
\hline CP1 Parties ${ }^{\mathrm{e}}$ & & 12,606 & $-17.2 \%$ & $-15.3 \%$ & $-25.3 \%$ & $-22.4 \%$ \\
\hline Likely CP2 Parties ${ }^{f}$ & & 7,399 & $-18.4 \%$ & $-17.5 \%$ & $-27.8 \%$ & $-25.1 \%$ \\
\hline
\end{tabular}

a Base year emissions are from the 2012 GHG inventories. Emission targets refer to all GHG emissions relevant under the Kyoto Protocol (Annex A). Base year emissions and emission targets do not include LULUCF unless otherwise specified below

b Australia's targets of $-5 \%$ (low pledge) and $-25 \%$ (high pledge) are relative to 2000 , and include AR and D emissions (we assume $34 \mathrm{Mt} \mathrm{CO}_{2}$ eq, i.e. the average of 2013-2020 country's projections, see Table 1). In this Table, targets are expressed both relative to 1990 and 2000; in both cases, AR and D emissions are included (140 Mt $\mathrm{CO}_{2}$ eq in 1990 and $71 \mathrm{Mt} \mathrm{CO}$ eq in 2000, from $2012 \mathrm{GHG}$ inventory). The potential additional contribution of LULUCF to the pledges is estimated as the difference between Table 2 and in Table 1 (i.e., 17 $\mathrm{Mt} \mathrm{CO}_{2}$ eq, or $3 \%$ relative to 2000). See text for further details

${ }^{\mathbf{c}}$ For the EU's low pledge scenario, we assumed no LULUCF credits to be included

${ }^{\mathbf{d}}$ For Norway, base year emissions include LULUCF (UNFCCC 2012b)

e Sum of Parties above

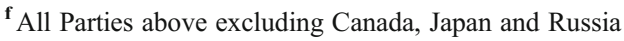

uncertainties are linked to possible natural disturbances, ${ }^{16}$ whose impact on FM may be excluded with the rules agreed in Durban.

When comparing the potential LULUCF credits for the 2013-2020 period with the expected credits during the CP1 (using the JRC LULUCF tool), the order of magnitude is similar for the

\footnotetext{
${ }^{16}$ For instance, according to the review of Canada's submission on FMRL (http://unfecc.int/resource/docs/ 2011/tar/can01.pdf), the order of magnitude of the impact on Canada's FMRL of delayed emissions and reduced removals due to insects is about $10 \%$ of 1990 country's emissions.
} 
Annex I Parties as a whole (i.e. credits up to about $2 \%$ of base year emissions), for the likely CP2 Parties, and for most individual Parties.

\section{Conclusions: LULUCF makes the difference for some parties}

This paper presents some key differences among Parties in the minimum (assuming no additional action) and potential (assuming additional actions) contribution by the main LULUCF activities (AR, D and FM) to achieving the pledges submitted by the Parties in the Cancún Agreements. Despite this analysis being based on a number of, in some cases, quite crude and uncertain assumptions, we believe that the main differences highlighted are robust and reflect different characteristics of the LULUCF sectors (i.e. the relative importance of forest emissions or removals compared to each Party's base year emissions).

On FM where the reference levels are based on 1990 emissions (e.g. Russia, Norway) or are equal to zero (Japan), substantial credits are expected even without additional actions. At the same time, a cap limits the FM credits to $3.5 \%$ of base year emissions (without LULUCF, unless otherwise specified). Given the lack of a cap on AR or D, the contribution from these activities is fully reflected in the accounting. For New Zealand this implies that LULUCF credits, mainly from AR, may contribute by up to $33 \%$ of its base year emissions. For Australia, when the foreseen (based on Australia's projections) and potential future emissions from LULUCF are compared to the AR and D emissions included in 1990 and 2000 emissions levels, the role of LULUCF to meet the pledges appears to range from a minimum of about $19 \%$ and $7 \%$ (relative to 1990 and 2000, respectively) to a potential of about $22 \%$ and $10 \%$ (relative to 1990 and 2000, respectively). For the EU, the overall contribution of LULUCF credits is expected to be relatively modest compared to its pledges ( $0.5 \%$ to $1.8 \%$ of its 1990 emissions).

Overall, this analysis clearly indicates that, whereas the overall contribution of LULUCF in the period 2013-2020 seems to be relatively modest for CP1 Parties (credits up to about $2 \%$ of base year emissions, comparable to what is expected during the CP1), and also for the likely CP2 Parties (credits up to $1.5 \%$ relative to 1990 emissions), for specific Parties LULUCF credits or debits can make a substantial difference in the reduction pledges.

Disclaimer The views expressed are purely those of the authors and may not in any circumstances be regarded as stating an official position of the European Commission.

Open Access This article is distributed under the terms of the Creative Commons Attribution License which permits any use, distribution, and reproduction in any medium, provided the original author(s) and the source are credited.

\section{References}

Böttcher H, Verkerk PJ, Gusti M, Havlik P, Grassi G (2012) Projection of the future EU forest $\mathrm{CO}_{2}$ sink as affected by recent bioenergy policies using two advanced forest management models. Glob Chang Biol Bioenergy. doi:10.1111/j.1757-1707.2011.01152.x

den Elzen MGJ, Hof AF, Mendoza Beltran A, Grassi G, Roelfsema M, van Ruijven BJ, van Vliet J, Van Vuuren DP (2011) The Copenhagen accord: abatement costs and carbon prices resulting from the submissions. Environ Sci Policy 14:28-39 
Grassi, G. (2012a) LULUCF: a major step in Durban, EFI News 1, 10-11 http://www.efi.int/files/attachments/ publications/efi_news_final_1_12_net.pdf.

Grassi G. (2012b) JRC LULUCF tool, version 18 June 2012, http://afoludata.jrc.ec.europa.eu/index.php/ models/JRC_LULUCF_TOOL.

IPCC (2006) 2006 IPCC Guidelines for National GHG Inventories. prepared by the National GHG Inventories Programme. H.S. Eggleston, L. Buendia, K. Miwa, T. Ngara and K. Tanabe (eds). Institute for Global Environmental Strategies, Hayama, Japan.

Macintosh AK (2011) Are forest management reference levels incompatible with robust climate outcomes? A case study on Australia. Carbon Manag 2(6):1-17

UNFCCC. (2010). Decision 1/CP.16, The Cancun Agreements. UNFCCC document FCCC/CP/2010/7/ Add.1, http://unfccc.int/resource/docs/2010/cop16/eng/07a01.pdf\#page=2

UNFCCC (2012a) Decision 2/CMP.7 Land use, land-use change and forestry, http://unfccc.int/resource/docs/ 2011/cmp7/eng/10a01.pdf\#page=11.

UNFCCC (2012b) Quantified economy-wide emission reduction targets by developed country Parties to the Convention. UNFCCC document FCCC/TP/2012/2, http:/unfccc.int/resource/docs/2011/tp/01.pdf. 